\title{
Characteristics of Family Medicine Residency Graduates, 1994-2017: An Update
}

\author{
Mingliang Dai, $P b D^{1}$ \\ Lars E. Peterson, MD, $\mathrm{PbD}^{1,2}$ \\ ${ }^{1}$ American Board of Family Medicine, \\ Lexington, Kentucky \\ ${ }^{2}$ Department of Family and Commu- \\ nity Medicine, University of Kentucky, \\ Lexington, Kentucky
}

\begin{abstract}
PURPOSE The purpose of this study was to characterize graduates of family med-
icine (FM) residencies from 1994 to 2017 and determine whether they continue
to practice family medicine after residency.
ABSTRACT
PURPOSE The purpose of this study was to characterize graduates of family med-
icine (FM) residencies from 1994 to 2017 and determine whether they continue
to practice family medicine after residency.

ABSTRACT
PURPOSE The purpose of this study was to characterize graduates of family med-
icine (FM) residencies from 1994 to 2017 and determine whether they continue
to practice family medicine after residency.

ABSTRACT
PURPOSE The purpose of this study was to characterize graduates of family med-
icine (FM) residencies from 1994 to 2017 and determine whether they continue
to practice family medicine after residency.

METHOD We sampled physicians who completed FM residency training from 1994-2017 using 2017 American Medical Association (AMA) Physician Masterfile linked with administrative files of the American Board of Family Medicine (ABFM). The main outcomes measured were characteristics of FM residency graduates, including medical degree type (Doctor of Medicine, MD vs Doctor of Osteopathic Medicine, DO), international medical school graduates (IMGs) vs US graduates, sex, ABFM certification status, and self-designated primary specialty. Family medicine residency graduates were grouped into 4-year cohorts by year of residency completion.
\end{abstract}

RESULTS From 1994 to 2017, 66,778 residents completed training in an ACGME accredited FM residency, averaging 2,782 graduates per year. The number of FM residency graduates peaked in 1998-2001, averaging 3,053 each year. The composition of FM residents diversified with large increases in DOs, IMGs, and female graduates over the past 24 years. Of all the FM residency graduates, $91.9 \%$ claimed FM as their primary specialty and $81 \%$ were certified with ABFM in 2017. FM/sport medicine (2.1\%), FM/geriatric medicine (0.9\%), internal medicine/geriatrics $(0.8 \%)$, and emergency medicine $(0.7 \%)$ were the most common non-FM primary specialties reported.

CONCLUSIONS DOs, IMGs, and female family medicine residency graduates increased from 1994 to 2017. With 9 in 10 graduates of family medicine residencies designating FM as their primary specialty, FM residency programs not only train but supply family physicians who are likely to remain in the primary care workforce.

Ann Fam Med 2020;18:370-373. https://doi.org/10.1370/afm.2535.

\section{INTRODUCTION}

Exacerbating the projected shortage of primary care physicians, ${ }_{1}^{1}$ only $10.9 \%$ US medical students entered family medicine (FM) training in 2016. ${ }^{2}$ In response, the American Academy of Family Physicians (AAFP), and 7 other family medicine organizations, started the $25 \times 2030$ initiative aiming to enroll 25\% of medical school seniors in FM training by 2030 by enhancing mentoring and medical student choice of FM. ${ }^{3}$ Completing residency in primary care specialties, however, does not guarantee that residents will continue to practice primary care. ${ }^{4,5}$ The only comprehensive review of FM residency graduates from 1969 to 1993 found that 89.4\% identified their primary specialty as family medicine. ${ }^{6}$ Since that report, widening income differentials relative to specialists, ${ }^{7}$ and rising burnout among early career family physicians $(\mathrm{FPs})^{8}$ raises concerns about how well family medicine retains its graduates. Our objective is to examine the characteristics of graduates of family medicine residencies from 1994 to 2017, describe temporal trends, and determine whether they continue to identify family medicine as their primary specialty.

\section{CORRESPONDING AUTHOR}

Mingliang Dai, PhD

American Board of Family Medicine 1648 McGrathiana Parkway, Suite 550 Lexington KY 40511-1247 mdai@theabfm.org 


\section{METHODS}

\section{Data}

We used 2017 American Medical Association (AMA)

Physician Masterfile (Masterfile) to obtain information on physicians' current self-designated primary specialty, residency specialty, and training duration. We linked the AMA Masterfile with the diplomate file of American Board of Family Medicine (ABFM) by national provider index (NPI) to determine ABFM certification in 2017.

\section{Sample}

We identified residents in the AMA Masterfile whose residency specialty was FM, FM/sports medicine, FM/ preventive medicine, FM/psychiatry, FM/emergency medicine, or FM/internal medicine. We restricted to residents who completed 3 or 4 years of FM training (ie, the lengths of training in FM residencies) and those whose last 2 years of FM training was with the same residency (ie, an ABFM requirement). Our analytical sample included 66,778 graduates of ACGME accredited FM residencies from 1994 to 2017.

\section{Measures}

We obtained personal characteristics of FM residency graduates, including type of medical degree (MD vs DO), international medical school graduates (IMGs) vs US graduates, and sex from the AMA Masterfile. Primary specialties of FM residency graduates were obtained from self-designated specialty in the AMA Masterfile, which is updated by the AMA routinely. FPs were certified with ABFM in 2017 if they matched with ABFM administrative files by NPI and their certification expiration date was $\geq 2018$. We used last year of FM residency training as year of residency completion and captured the specialty of the most recent training.

\section{Analysis}

We examined the distributions of FM residency graduates by personal characteristics and certification status in 2017. We grouped graduates into 1 of 6 4-year cohorts, eg, 19941997... 2014-2017, by their year of residency completion. We listed most frequently designated primary specialties based on the percentage of FM residency graduates and then stratified the percentages by whether the last training was in FM. Lastly, we examined the characteristics of FM residency graduates by the most-designated primary specialties. All analyses were conducted with SAS Version 9.4 (SAS Institute Inc). This research protocol was approved by the AAFP Institutional Review Board.

\section{RESULTS}

From 1994 to 2017, 66,778 residents completed training in an ACGME-accredited FM residency, averaging 2,782 graduates per year (Table 1 ). The number of graduates peaked during 1998-2001, averaging 3,053 each year. The percentage of DOs had increased gradually from less than $10 \%$ prior to 2002 to $12.3 \%$ in 2014-2017. The percentage of IMGs in 2014-2017 more than doubled over our study period from $18 \%$ to $37 \%$. Females became the majority of graduates in number in 2002-2005. In 2017, 81.4\% of all FM residency graduates were certified with ABFM.

The 20 most frequently designated primary specialties of FM graduates are shown in Table 2. Overall, FM was claimed by $91.9 \%$ of FM residency graduates as their primary specialty, followed by FM/sports medicine $(2.2 \%)$, FM/geriatric medicine $(0.9 \%)$, internal medicine/geriatrics $(0.9 \%)$, and emergency medicine $(0.7 \%)$. Among those whose last training was in FM $(\mathrm{n}=62,076), 98 \%$ claimed FM as their primary specialty. For those whose last training was not in FM (n $=4,702), 29.8 \%$ claimed FM/ sports medicine, $12.1 \%$ internal medicine/geriatric, $11.8 \% \mathrm{FM} /$ geriatric medicine (ie, training programs that could lead to certificates of added qualifications sponsored by ABFM), and $10.6 \%$ still claimed FM as their primary specialty.

Personal characteristics and board certification status varied by self-designated primary specialty (Table 3). For example, $11.9 \%$ of FM residency graduates who designated FM as primary specialty were DOs compared to $28.9 \%$ among those who designated general practice. IMGs constituted $28.6 \%$ of residency graduates who claim FM as primary specialty, much lower than specialties such as sleep medicine $(77.4 \%)$ and
Table 1. Characteristics of FM Residency Graduates, 1994-2017

\begin{tabular}{|c|c|c|c|c|c|}
\hline Time Span & Total & $\%$ DO & $\%$ IMGs & $\%$ Female & $\begin{array}{l}\% \text { ABFM } \\
\text { Certified } \\
\text { in } 2017\end{array}$ \\
\hline 1994-1997 & 9,062 & $776(8.6)$ & 1,638 (18.1) & $3,610(39.8)$ & $6,773(74.7)$ \\
\hline 1998-2001 & 12,212 & 1,167 (9.6) & $1,572(12.9)$ & $5,496(45.0)$ & $9,420(77.1)$ \\
\hline $2002-2005$ & 11,661 & $1,487(12.8)$ & $2,965(25.4)$ & $5,849(50.2)$ & 9,627 (82.6) \\
\hline 2006-2009 & 11,578 & 1,688 (14.6) & $4,527(39.1)$ & $6,093(52.6)$ & $9,270(80.1)$ \\
\hline $2010-2013$ & 11,361 & $1,473(13.0)$ & $4,638(40.8)$ & $6.267(55.2)$ & $9,993(88.0)$ \\
\hline 2014-2017 & 10,904 & $1,337(12.3)$ & $4,049(37.1)$ & $5,909(54.2)$ & $9,262(84.9)$ \\
\hline 1994-2017 & 66,778 & 7,928 (11.9) & $19,389(29.0)$ & $33,224(49.8)$ & $54,345(81.4)$ \\
\hline
\end{tabular}


Table 2. Most Frequently Self-Designated Primary Specialty of Family Medicine Residency Graduates, 1994-2017, Sorted by $\%$ Overall

\begin{tabular}{|c|c|c|c|c|}
\hline & Primary Specialtya & $\begin{array}{c}\% \text { Overall } \\
(n=66,778)\end{array}$ & $\begin{array}{c}\% \text { Last } \\
\text { Training in FM } \\
(n=62,076)\end{array}$ & $\begin{array}{l}\% \text { Last Training } \\
\text { Not in FM } \\
(n=4,702)\end{array}$ \\
\hline 1 & Family medicine & 91.9 & 98.0 & 10.6 \\
\hline 2 & $\begin{array}{l}\text { Family medicine/sports } \\
\text { medicine }^{b}\end{array}$ & 2.2 & 0.1 & 29.8 \\
\hline 3 & $\begin{array}{l}\text { Family medicine/ } \\
\text { geriatric medicine }\end{array}$ & 0.9 & 0.0 & 11.8 \\
\hline 4 & $\begin{array}{l}\text { Internal medicine/ geri- } \\
\text { atric medicine }\end{array}$ & 0.9 & 0.0 & 12.1 \\
\hline 5 & Emergency medicine & 0.7 & 0.5 & 2.4 \\
\hline 6 & $\begin{array}{l}\text { General preventive } \\
\text { medicine }\end{array}$ & 0.4 & 0.0 & 5.1 \\
\hline 7 & $\begin{array}{l}\text { Hospice \& palliative } \\
\text { medicine }^{b}\end{array}$ & 0.3 & 0.0 & 4.6 \\
\hline 8 & Obstetrics \& gynecology & 0.2 & 0.0 & 2.8 \\
\hline 9 & Urgent care medicine & 0.2 & 0.2 & 0.1 \\
\hline 10 & Hospitalist & 0.2 & 0.2 & 0.1 \\
\hline 11 & Internal medicine & 0.2 & 0.1 & 1.6 \\
\hline 12 & $\begin{array}{l}\text { Family medicinel } \\
\text { psychiatry }\end{array}$ & 0.1 & 0.0 & 1.9 \\
\hline 13 & Psychiatry & 0.1 & 0.0 & 1.5 \\
\hline 14 & Dermatology & 0.1 & 0.0 & 0.8 \\
\hline 15 & Occupational medicine & 0.1 & 0.0 & 0.7 \\
\hline 16 & Anesthesiology & 0.1 & 0.0 & 1.2 \\
\hline 17 & Sleep medicine ${ }^{b}$ & 0.1 & 0.0 & 1.2 \\
\hline 18 & General practice & 0.1 & 0.1 & 0.1 \\
\hline 19 & Diagnostic radiology & 0.1 & 0.0 & 1.0 \\
\hline \multirow[t]{2}{*}{20} & $\begin{array}{l}\text { Family medicine/inter- } \\
\text { nal medicine }\end{array}$ & 0.1 & 0.0 & 0.8 \\
\hline & Other specialties & 1.0 & 0.4 & 9.4 \\
\hline
\end{tabular}

FM as their primary specialty-a $2.5 \%$ improvement on physician retention compared to $1969-1993 .{ }^{6}$ The number of fellowship opportunities that can lead to FM board certification is limited compared to other primary care specialties such as internal medicine, ${ }^{11}$ which could contribute to the high percentage of FPs who designated FM as their primary specialty. If residency graduates continue to practice FM at a $90 \%$ level, AAFP's $25 \times 2030$ initiative could lead to a future output of $22.5 \%$ of medical students providing primary care. ${ }^{12,13}$

This report continues efforts to measure outputs of FM residency training. On average, FM residencies graduated 2,782 residents each year 1994-2017, nearly 400 more than the annual average during 1969-1993. ${ }^{6}$ The peak supply of FM residency graduates during 1998 2001 corresponded to the brief surge in the number of primary care physicians after mid-1990s when health maintenance organizations promoted primary care physicians as gatekeepers in their care delivery model. ${ }^{14}$ Compared to $1969-1993$, self-designated primary specialties of FM graduates were comparable except that FM/sports medicine has replaced emergency medicine as the second most-designated spe-

internal medicine/geriatrics (65.5\%). Although female graduates comprised more than one-half of those who designated FM or a combined FM specialty as primary specialty, they were far less represented in $\mathrm{FM}$ /sports medicine $(24.7 \%)$, emergency medicine $(15.6 \%)$, anesthesiology (19\%), and diagnostic radiology (4.3\%). Among those who designated FM as primary specialty, 81.9\% were certified with ABFM in 2017.

\section{Discussion}

With an estimated shortage of primary care physicians and rapid growth of hospitalists, ${ }^{1,9}$ we found that FM residency training both supplies and retains physicians in the primary care workforce, a prerequisite for the Triple Aim: better patient experience, better population health, and lower costs. ${ }^{10}$ From 1994 to 2017, 91.9\% of all graduates of FM residencies (and 98\% of those whose last training was in FM) self-designated cialty. Substantial increases in DOs, IMGs, and female graduates in our study, concurring with greater racial and ethnic diversity in FM residents documented elsewhere, shows a diversifying FP workforce. ${ }^{15,16}$

\section{Limitations}

This study has several limitations. First, self-designated specialty may not represent major clinical activity. For example, FPs may not designate as urgent care yet still practice in that setting. In particular, this potential classification error may have led to a considerable undercount of FPs who work as hospitalists but have not changed their designation. We found $<1 \%$ of the physicians self-designated hospitalist $(0.12 \%$ as primary specialty and $0.16 \%$ as secondary specialty), much lower than $9 \%$ found in a study of 2013 FM residency graduates. ${ }^{4}$ Lastly, we weren't able to distinguish between combined and sequential training, eg, 
Table 3. Characteristics of Family Medicine Residency Graduates by Primary Specialty, 1994-2017

\begin{tabular}{|c|c|c|c|c|c|}
\hline Primary Specialty & No. & $\% \mathrm{DO}$ & $\%$ IMG & $\begin{array}{c}\% \\
\text { Female }\end{array}$ & $\begin{array}{l}\% \text { ABFM } \\
\text { Certified } \\
\text { in } 2017\end{array}$ \\
\hline Family medicine & 61,362 & 11.9 & 28.6 & 50.8 & 81.9 \\
\hline $\begin{array}{l}\text { Family medicine/sports } \\
\text { medicine }\end{array}$ & 1,435 & 17.1 & 19.4 & 24.7 & 93.4 \\
\hline $\begin{array}{l}\text { Family medicine/geriatric } \\
\text { medicine }\end{array}$ & 575 & 4.9 & 52.2 & 58.4 & 87.5 \\
\hline $\begin{array}{l}\text { Internal medicine/geriatric } \\
\text { medicine }\end{array}$ & 571 & 6.3 & 65.5 & 58.8 & 87.7 \\
\hline Emergency medicine & 442 & 12.4 & 26.9 & 15.6 & 68.3 \\
\hline General preventive medicine & 246 & 6.9 & 21.1 & 47.2 & 69.5 \\
\hline Hospice \& palliative medicine & 221 & 14.9 & 33.9 & 65.2 & 95.9 \\
\hline Obstetrics \& gynecology & 152 & 6.6 & 40.1 & 43.4 & 48.0 \\
\hline Urgent care medicine & 149 & 9.4 & 41.6 & 39.6 & 75.8 \\
\hline Hospitalist & 135 & 5.1 & 45.6 & 32.4 & 86.8 \\
\hline Internal medicine & 134 & 11.2 & 48.5 & 38.8 & 52.2 \\
\hline Family medicine/psychiatry & 92 & 8.7 & 6.5 & 53.3 & 78.3 \\
\hline Psychiatry & 76 & 10.5 & 18.4 & 42.1 & 30.3 \\
\hline Dermatology & 65 & 20.0 & 15.4 & 49.2 & 26.2 \\
\hline Occupational medicine & 63 & 16.1 & 29.0 & 25.8 & 56.5 \\
\hline Anesthesiology & 62 & 11.1 & 19.0 & 19.0 & 34.9 \\
\hline Sleep medicine & 62 & 1.6 & 77.4 & 45.2 & 87.1 \\
\hline General practice & 46 & 28.9 & 26.7 & 31.1 & 42.2 \\
\hline Diagnostic radiology & 45 & 10.9 & 15.2 & 4.3 & 23.9 \\
\hline $\begin{array}{l}\text { Family medicine/internal } \\
\text { medicine }\end{array}$ & 38 & 13.2 & 18.4 & 47.4 & 89.5 \\
\hline
\end{tabular}

\section{Reference}

1. Health Resources \& Services Administration. National and regional projections of supply and demand for primary care practitioners: 2013-2025. https://bhw.hrsa.gov/health-workforce-analysis/research/projections. Published 2016. Accessed Sep 4, 2018.

2. Kozakowski SM, Travis A, Marcinek JP, Bentley A, Fetter GT Jr. Entry of medical school graduates into family medicine residencies: 2016 2017. Fam Med. 2017;49(9):686-692.

3. American Academy of Family Physicians. AAFP hosts launch of $25 \times 2030$ student choice collaborative. https://www. aafp.org/news/education-professionaldevelopment/20180905twentyfiveby2030. html. Published Sep 5, 2018. Accessed Mar 19, 2019

4. Kamerow DB, Wingrove $P$, Petterson $S$, Peterson L, Bazemore A. Characteristics of young family physician hospitalists. J Am Board Fam Med. 2018;31(5):680-681.

5. Petterson S, Peterson L, Phillips RL, et al. One in fifteen family physicians principally provide emergency or urgent care. J Am Board Fam Med. 2014;27(4):447-448.

6. Kahn NB Jr, Schmittling G, Ostergaard D, Graham R. Specialty practice of family practice residency graduates, 1969 through 1993. A national study. JAMA. 1996;275(9):713-715.

7. Bodenheimer $T$, Berenson RA, Rudolf $P$. The primary care-specialty income gap: why it matters. Ann Intern Med. 2007;146(4):301-306.

8. Hansen A, Peterson LE, Fang B, Phillips RL Jr. Burnout in young family physicians: variation across states. J Am Board Fam Med. 2018;31(1): 7-8.

9. Wachter RM, Goldman L. Zero to 50,000 - the 20th anniversary of the hospitalist. N Engl J Med. 2016;375(11):1009-1011.

10. Berwick DM, Nolan TW, Whittington J. The triple aim: care, health, and cost. Health Aff (Millwood). 2008;27(3):759-769.

11. American Board of Medical Specialties. ABMS board certification report. https://www.abms.org/board-certification/abms-boardcertification-report/. Published 2019. Accessed Nov 14, 2019.

12. Phillips RL Jr, Bazemore AW. Primary care and why it matters for U.S. health system reform. Health Aff (Millwood). 2010;29(5):806-810.

13. Council on Graduate Medical Education. 20th report: advancing primary care. https://www.hrsa.gov/advisorycommittees/bhpradvisory/ cogme/Reports/twentiethreport.pdf. Accessed Mar 212019.

14. Steinwald B. Primary care professionals: recent supply trends, projections, and valuation of services. Testimony before the Committee on Health, Education, Labor, and Pensions, U.S. Senate. https:// www.gao.gov/new.items/d08472t.pdf. Published Feb 12, 2008. Accessed Sep 5, 2018.

15. Xierali I, Hughes L, Nivet M, Bazemore A. Family medicine resident: increasingly diverse, but lagging behind underrepresented minority population trends. 2014. https://www.graham-center. org/rgc/publications-reports/publications/one-pagers/increasinglydiverse-2014.html. Accessed Sep 5, 2018.

16. Grumbach K, Mendoza R. Disparities in human resources: addressing the lack of diversity in the health professions. Health Aff (Millwood). 2008;27(2):413-422.

Key words: family medicine; residency graduates; primary specialty

Previous presentation: Presented at 2018 American Board of Medical Specialties Annual Meeting, Sep 24-26, 2018; Las Vegas, Nevada. 